\title{
Perancangan Perbandingan Jumlah Hop Pada Wireless Mesh Network
}

\author{
Hery Nurmawan ${ }^{1}$, Bambang Soedijono ${ }^{2}$, Eko Pramono $^{3}$ \\ ${ }^{123}$ Magister Teknik Informatika, Univeristas AMIKOM Yogyakarta \\ Email : ${ }^{1}$ hery.nurmawan@students.amikom.ac.id, ${ }^{2}$ bambang.s@amikom.ac.id , ${ }^{3}$ \\ eko.p@amikom.ac.id
}

\begin{abstract}
Abstrak
Wireless Mesh Network (WMN) adalah jaringan nirkabel yang memiliki kemampuan untuk megkonfigurasi dirinya sendiri (self-configure) dan mengorganisasi dirinya sendiri (selforganizing). Jaringan ini biasanya diimplementasikan pada perangkat keras 802.11. WMN terdiri dari beberapa node yang membentuk backbone jaringan. Node-node tersebut mampu mengkonfigurasi secara otomatis dan me-rekonfigurasi secara dinamis untuk menjaga konektivitas jaringan. WMN banyak diterapkan untuk mengatasi masalah keterbatasan jangkauan access point pada wireless LAN. Untuk mendapatkan kinerja yang optimal pada WMN diperlukan teknik pemaangan hop pada WMN. Perancangan pemasnagan Hop pada ruang bertingkat dan bersekat, berbeda dengan pemasangan pada aula atau tempat tanpa sekat. Dengan jumlah router maksimal 8 buah, peneltian ini mengggunakan skema jumlah ganjil dan genap dalam pengujiannya. Hasil dari perancangan ini diprediksi bahwa implementasi pada ruang aula dan tanpa sekat lebih baik daripada implementasi pada ruang bertingkat dan bersekat.
\end{abstract}

Kata Kunci:wireless mesh network, self confident, jumlah hop

\section{PENDAhuluan}

Wireless Mesh Network merupakan teknologi jaringan tanpa kabel yang banyak digunakan sebagai pengganti jaringan Wireless LAN biasa. Wireless Mesh Network (WMN) banyak digunakan karena mempunya kemampuan untuk mengkonfigurasi dirinya sendiri (self-Configure), mengorganisasi dirinya sendiri (self-organizing) dan tidak tergantung dengan server (autonomous). Wireless Mesh Network (WMN) tersusun dari beberapa Hop yang suatu backbone jaringan, dimana setiap Hop dapat mengkonfigurasi dan mengorganisir dirinya sendiri secara otomatis diimplementasi (Fauzan Fadillah, Istikmal, Ratna Mayasari,2012).

Wireless Mesh Network (WMN) banyak diimplementasikan pada area-area seperti pendidikan, perkantoran maupun area publik dengan tingkat pengguna internet yang tinggi. Dalam implementasi Wireless LAN pada area gedung maupun area publik ternyata ada beberapa kendala yang muncul, seperti keterlambatan pengiriman data, koneksi tidak stabil, interferensi frekuensi dan sebagainya (Maulida Fitriani, Nachwan Mufti, ST., MT., Tody Ariefianto, ST., MT, 2016). Desain tata ruang merupakan salah satu faktor yang mempengaruhi kinerja pada Wireless Mesh Network (WMN). Banyak sedikitnya jumlah Hop merupakan kendala yang paling besar pengaruhnya terhadap kinerja Wireless Mesh Network (WMN).

Penelitian terkait dengan studi kasus pada lingkungan kampus untuk melakukan identifikasi dampak dari penggantian jaringan WLAN biasa menjadi Wireless Mesh Network (WMN). Penelitian tersebut mengimplementasikan Wireless Mesh Network yang menggunakan protokol Mesh Made Easy (MME) sehingga dengan penerapan jaringan menggunakan WMN dapat diakses secara mobile. Controller Access Point System Manager (CAPSMAN) merupakan sebuah pengontrol jaringan Wireless yang dilakukan secara terpusat sehingga memudahkan administrator dalam pengontrolan jaringan. Network Development Life Ciycle (NDLC) merupakan metode yang digunakan dalam tahapan penerepaan jaringan WMN (Januar Al Amien, Cuncun Wibowo, 2017).

Performa Wireless Mesh Network (WMN) dipengaruhi oleh tata ruang maupun material yang menghalangi. , maka perlu adanya rancangan mekanisme pengiriman 
informasi yang efisien. Penelitian yang dilakukan tersebut memberikan solusi pengiriman informasi menggunakan arsitektur publish subscribe. (Kasyful Amron1, Eko Sakti P, Mahendra Data, 2016).

Penelitian ini meneliti tentang pengaruh pemasangan Hop dengan jumlah ganjil dan genap terhadap Quality Of Service (QOS) Wireless Mesh Network (WMN). Ada beberapa penelitian yang mendasarai penelitian ini. Penelitian Sofyan Ainurrachman, dkk (2017) membahas tentang kehandalan kinerja security dari protocol OLSR dan SOLSR pada Mesh Network. Penelitian Kasyful Amron dkk (2016) membahas tentang memberikan solusi pengiriman informasi menggunakan arsitektur publish subscribe. Penelitian Fathur Zaini Rachman dkk (2017) membahas tentang performa QOS Wireless Mesh Network jika dilakukan penjadwalan distribusi. Penelitian Maulida Fitriani dkk (2016) membahas tentang Implementasi WMN pada Univeristas Muhammadiyah Riau. Penelitian Imam Tri Suryadin dkk (2016) membahasa tentang implementasi Wireless Mesh Network $(\mathrm{WMN})$ di alun-alun Purworejo. Penelitian Shinji Sakamoto dkk (2016), membahas tentang simulasi Swarm Optimization untuk memecahkan masalah jalur router pada Wireless Mesh Network (WMN).

Berdasarkan permasalahan yang telah dijelaskan pada latar belakang masalah, penelitian ini menekankan pada permasalahan pokok yang terkait tentang Wireless Mesh Network antara lain bagaimana membandingkan kinerja Wireless Mesh Network dengan jumlah Hop genap dan ganjil dengan pendekatan Real Eksperiment, berapa tingkat throughput, jitter, delay, dan packet loss dari perbandingan jumlah Hop pada Wireless Mesh Network, bagaimana kinerja Wireless Mesh Network pada desain ruangan yang berbeda, bagaimana meningkatkan kualitas pancaraan wireless pada Wireless Mesh Network?

Dari penelitian yang dilakukan tersebut tentang Wireless Mesh Network dapat mencapai tujuan penelitan antara lain dapat mengetahui koneksi yang berjalan pada Wireless Mesh Network jika jumlah Hop Ganjil atau genap, dapat mengetahui kinerja throughput, delay, jitter dan packet loss yang berjalan pada Wireless Mesh Network jika jumlah Hop ganjil atau genap, dapat mengetahui kinerja Wireless Mesh Network pada desain ruangan yang berbeda, meningkatkan kualitas perencanaan pemasangan wifi.

\section{METODE PENELITIAN}

Metode penelitian yang dilakukan pada penelitian ini dilakukan dalam beberapa tahap, meliputi metode pengumpulan data yang dilakukan dalam penelitian ini melalui suatu eksperimen yang dijelaskan dalam sebagai berikut antara lain studi pustaka, tahap ini dilakukan dengan cara mencari dan membaca literatur dan referensi tentang jaringan komputer, Wireless LAN, dan Wireless Mesh Network (WMN). Selain itu, pada tahap ini juga dilakukan pemilihan perangkat keras yang cocok digunakan untuk Wireless Mesh Network (WMN). Data yang dikumpulkan berupa angka maupun grafik, perolehan data yang diambil bersifat realtime yang merupakan hasil dari eksperimen Wireless Mesh Network. Proses kerja yang dilakukan dalam penelitian ini, mengambil hasil dari skenario jaringan yang diterapkan. Skenario yang diterapakan meliputi jumlah Hop dan penempatan Hop pada tata ruang yang ada. Desain tata ruang terdiri dari dua model yaitu model ruang bertingkat dan aula..

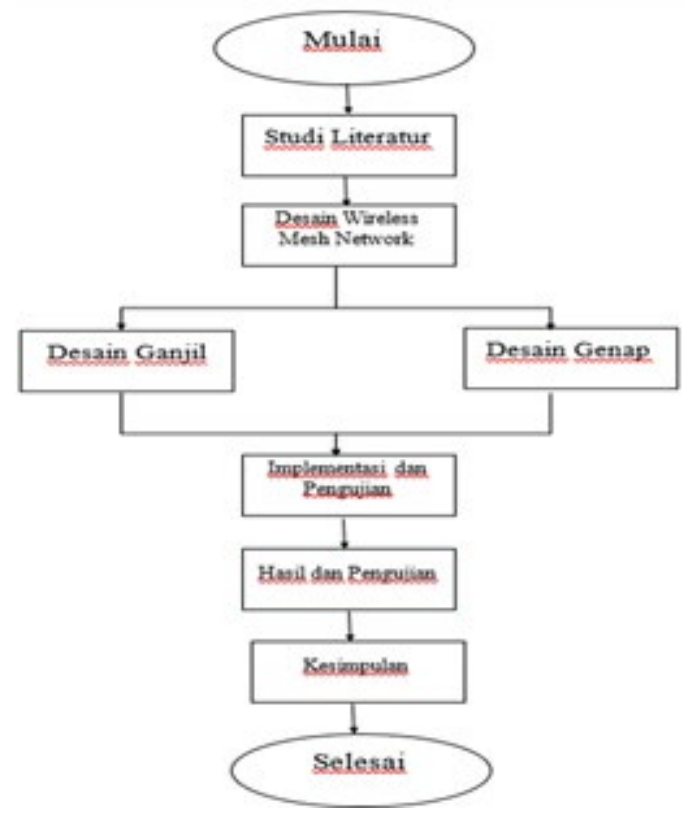

Gambar 1. Alur Penelitian

Pada gambar 1 dijelaskan tentang alur penelitian mulai dari studi literature, design wireless mesh network, pada desain tersebut 
dibagi menjadi dua yaitu desain ganjil dan desain genap, kemudian diimplementasikan dan dilakukan pengujian, dari proses pengujian akan diperoleh hasil tentang perbandingan design ganjil dan desain genap.

\section{TINJAUAN PUSTAKA}

a. Penelitian Terdahulu

Banyak penelitian tentang Wireless Mesh Network (WMN) yang telah dilakukan, salah satunya penelitian yang berkaitan dengan perbandingan routing OLSR dan SOLSR pada konfigurasi Wireless Mesh Network. Tujuan dari penelitian ini adalah mengukur kehandalan kinerja security dari protocol OLSR dan SOLSR pada Mesh Network. Hasil yang didapat dari penelitian ini adalah secara keseluruhan adanya tambahan mekanisme keamanan pada SOLSR mempengaruhi performansi protokol routing yang lebih rendah dari protokol OLSR (Sofyan Ainurrachman, Adhitya Bhawiyuga, dan Mochammad Hannats Hanafi Ichsan, 2017).

Performa Wireless Mesh Network $(\mathrm{WMN})$ dipengaruhi oleh tata ruang maupun material yang menghalangi. , maka perlu adanya rancangan mekanisme pengiriman informasi yang efisien. Penelitian yang dilakukan tersebut memberikan solusi pengiriman informasi menggunakan arsitektur publish subscribe. Protokol publish subscribe yang digunakan adalah protokol MQTT (Message Queuing Telemetry Transport). Inti penelitian yang dilakukan yaitu pengujian terhadap Quality of Service seperti throughput, delay, jitter, dan packet loss untuk keseluruhan node. Pada pengujian QoS arsitektur WMN maupun MTQQ menunjukan bahwa kualitas layanan dipengaruhi oleh jarak,jumlah node yang dilewati dan material yang menghalang (Kasyful Amron1, Eko Sakti P, Mahendra Data, 2016).

Penelitian terkait dengan penjadwalan distribusi pada Wireless Mesh Network salah satunya penelitian tentang penggunaan Spatial Time Division Multiple Access (STDMA). Scheduling adalah salah satu aspek yang paling penting yang akan berdampak pada performansi sistem. Terdapat dua mekanisme scheduling, yakni centralized scheduling dan distributed scheduling. Penjadwalan distributed terbagi menjadi 2 yaitu coordinated, distributed, dan uncoordinated distributed. Tugas akhir ini menyajikan unjuk kerja algoritma skema dasar yang merupakan algoritma untuk coordinated, distributed, dan scheduling. Penggunaan STDMA merupakan solusi dari terbatasnya jumlah slot untuk pengalokasian node.

Skema perancangan sistem dalam penelitian ini dimulai dengan setting node secara acak. Node yang disetting ini memiliki letak yang dibuat random. Kemudian pada node yang disetting tersebut akan dihitung jarak dari masing-masing node. Setelah itu akan dilakukan penghitungan SNR dari masing- masing node yang telah dibangkitkan. Dari nilai SNR tersebut, akan dipilih modulasi yang akan digunakan untuk masing-masing node. Setelah memilih modulasi, kemudian setiap node akan dijadwalkan dengan skema dasar. Skema dasar memungkinkan pengalokasian minislot kosong secara terurut. Adapun penggunaan STDMA sendiri memungkinkan setiap slot tersebut dapat ditempati oleh beberapa node. Tahap terakhir adalah dilakukannya penghitungan throughput, dan fairness index dari sistem ini (Fathur Zaini Rachman, Armin, Nur Yanti, Qory Hidayati, 2017)

Penelitian terkait dengan studi kasus pada lingkungan kampus untuk melakukan identifikasi dampak dari penggantian jaringan WLAN biasa menjadi Wireless Mesh Network (WMN). Penelitian tersebut mengimplementasikan Wireless Mesh Network (WMN)yang menggunakan protokol Mesh Made Easy (MME) sehingga dengan penerapan jaringan menggunakan WMN dapat diakses secara mobile. Controller Access Point System Manager (CAPSMAN) merupakan sebuah pengontrol jaringan Wireless yang dilakukan secara terpusat sehingga memudahkan administrator dalam pengontrolan jaringan. Network Development Life Ciycle (NDLC) merupakan metode yang digunakan dalam tahapan penerepaan jaringan WMN. Dari hasil simulasi yang telah dilakukan dapat disimpulkan bahwa dengan menerapkan jaringan WMN dan menggunakan CAPSMAN jaringan Wireless dapat diakses hanya dengan menggunakan satu SSID dapat diakses secara mobile dan dapat memudahkan administrator dalam pengontrolan jaringan yang dilakukan secara terpusat ( Januar Al Amien, Cuncun Wibowo, 2017). 
Wireless Mesh Network (WMN) diimplementasikan pada area publik. Pada penelitian ini membahas tentang implementasi Wireless Mesh Network (WMN) pada alunalaun Purworejo. Pada alun-alun Purworejo sebelumnya mengimplementasi Wireless LAN, namun kinerja dari Wireless LAN tersebut dirasa kurang maksimal, maka diimplementasikan Wireless Mesh Network (WMN). Dengan imlementasi Wireless Mesh Network (WMN), maka koneksi hotspot di alun-alaun Purworejo dapat bekerja secara maksimal (Imam Tri Suryadin, Wing Wahyu Winarno, Sudarmawan, 2016).

Analisis perbandingan empat metode dalam Wireless Mesh Network (WMN). Pada penelitian tersebut menerapkan sistem simulasi berdasarkan Partikel Swarm Optimization (PSO) untuk memecahkan masalah penempatan jala router di WMN. Empat metode penggantian mesh router antara lain: Constriction Method (CM), Random Inertia Weight Method (RIWM), Linearly Decreasing Vmax Method (LDVM) and Linearly Decreasing Inertia Weight Method (LDIWM). Hasil simulasi yang disediakan, menunjukkan bahwa $\mathrm{CM}$ menyatu sangat cepat, namun memiliki kinerja terburuk di antara empat metode tersebut. Metrik kinerja dipertimbangkan adalah Size of Giant Component (SGC) dan Number of Covered Mesh Clients (NCMC). RIWM konvergen cepat dan kinerja yang baik. LDIWM adalah kombinasi dari RIWM dan LDVM. LDVM konvergen setelah 170 jumlah fase namun memiliki kinerja yang baik (Shinji Sakamoto, Tetsuya Oda, 2016).

\section{b. Landasan Teori}

1) Wireless LAN

Wireless LAN merupakan jaringan

lokal yang menggunakan gelombang radio (sinyal eletromagentis) sebagai media tranmisinya. Wireless LAN menggunakan algoritma CSMA (Cariier Sense Multiple Access) dengan mekanisme CA (Collision Avoidance), sebelum sebuah unit memulai transmisi (I Putu Agus Eka Pratama, 2015). Semakin banyak penggunanan gadget maka implementasi Wireless LAN semakin banyak dilakukan, terutama diarea publik, perkantoran maupun pendidikan.

\section{2) Mesh Network}

Mesh Network merupakan jaringan komputer yang dapat diimplementasikan pada media kabel maupun wireless, yang melibatkan minimal dua buah perangkat dengan ketersediaan infrastruktur pendukung didalamnya (router,proses routing, gateway) dan setiap komputer bersifat self configuration (melakukan konfigurasi sendiri) serta autonomous (tidak tergantung terhadap komputer server). (Daintre Network, 2014)

Wireless Mesh Network (WMN) merupakan Mesh Network yang sepenuhnya menggunakan media nirkabel (wireless). Jenis Mesh Network ini paling banyak digunakan saat ini, apalagi dengan dukungan konsep dan teknologi Internet Of Thing (IOT). (I Putu Agus Eka Pratama, 2015:30).

\section{HASIL DAN PEMBAHASAN}

Pada tahap ini dilakukan perancangan wireless mesh network dengan beberapa topologi dan desain ruangan.

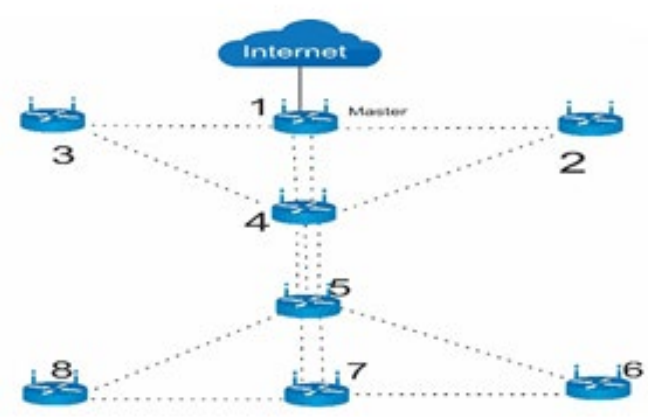

Gambar 2. Topologi Pada Bangunan Bertingkat

Pada gambar 2 dijelaskan tentang topologi yang aan digunakan pada bangunan bertingkat. Pada rancangan wireless mesh network ini menggunakan 8 router, untuk router 4 dan 5 merupakan penghubung antara lantai 1 dan lantai 2. 


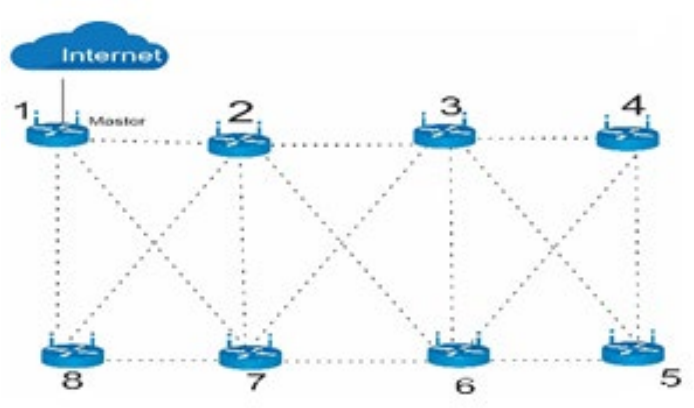

Gambar 3. Topologi Pada Aula

Pada gambar 3 dijelaskan tentang topologi pada aula, router yang digunakan sebanyak 8 buah yang dipasang pada ruangan yang tidak bersekat dan tidak bertingkat.

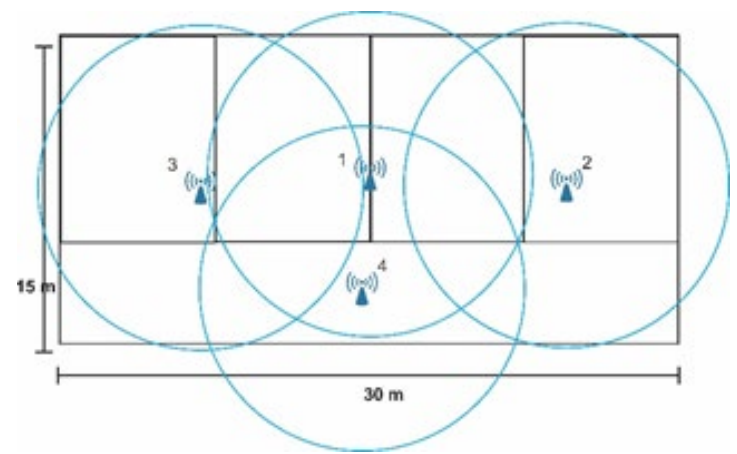

Gambar 4. Desain Ruang Tingkat Atas dan bawah

Pada Gambar 5 dijelaskan implementasi topologi pada ruangan bertingkat. Pada gambar tersebut juga diperlihatkan pancaran sinyal yang keluar dari masing-masing router. Dari pancaran sinyal tersebut dapat diketahui tentang batasan sinyal.

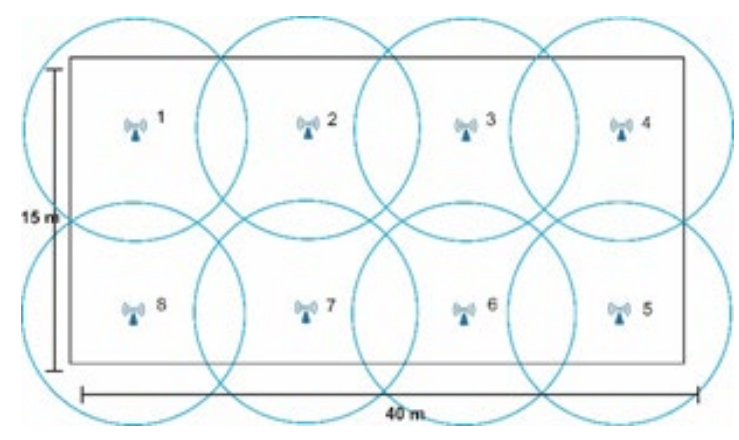

Gambar 5. Desain RuangAula

Pada gambar 5 dijelaskan tentang pemasangan router di ruang aula tanpa sekat. Pemasangan router pada aula dengan jumlah maksimal 8 router memungkinkan terjadi interferensi sinyal. Sinyal yang terpancar mempunyai

Tabel 1. Spesikasi Router Wireless

\begin{tabular}{|l|l|}
\hline Processor & $650 \mathrm{Mhz}$ \\
\hline Fast Ethernet & 4 port \\
\hline Wireless & $\begin{array}{l}2.4 \mathrm{Ghz} \\
(802.1 \mathrm{~b} / \mathrm{g} / \mathrm{n})\end{array}$ \\
\hline Antenna & $\begin{array}{l}\text { internal Dual- } \\
\text { Chain } 2 \mathrm{x} 1.5 \mathrm{dbi}\end{array}$ \\
\hline Product Code & RB941-2nD \\
\hline Architecture & SMIPS-BE \\
\hline CPU & QCA9531-BL3A- \\
& R 650MHz \\
\hline Current Monitor & No \\
\hline Main Storage/NAND & $16 \mathrm{MB}$ \\
\hline RAM & $32 \mathrm{MB}$ \\
\hline SFP Ports & 0 \\
\hline LAN Ports & 4 \\
\hline Gigabit & No \\
\hline Switch Chip & 1 \\
\hline MiniPCI & 0 \\
\hline Integrated Wireless & 1 \\
\hline Wireless Standarts & $802.11 \mathrm{~b} / \mathrm{g} / \mathrm{n}$ \\
\hline Wireless Tx Power & $22 \mathrm{dbm}$ \\
\hline Integrated Antenna & Yes \\
\hline Antenna Gain & $2 \mathrm{x} 1.5 \mathrm{dBi}$ \\
\hline MiniPCIe & 0 \\
\hline SIM Card Slots & No \\
\hline USB & No \\
\hline Memory Cards & No \\
\hline Power Jack & MicroUSB, 5v \\
\hline 802.3af Support & No \\
\hline POE Input & No \\
\hline POE Output & No \\
\hline Serial Port & No \\
\hline Voltage Monitor & No \\
\hline Temperature Sensor & No \\
\hline Dimentions & $113 \mathrm{x} 89 \mathrm{x} 28 \mathrm{~mm}$ \\
\hline Operating System & RouterOS \\
\hline Temperature Range & $-20 \mathrm{C}$ to $+70 \mathrm{C}$ \\
\hline & \\
\hline
\end{tabular}

Pada tabel 1 dijelaskan tentang hardware yang digunakan untuk penelitian tersebut. Hardware yang digunakan model mikrotik hap lite. Mikrotik hap lite digunakan karena kemudahan beberapa fitur yang bisa digunakan untuk mengecek delay, jitter, transfer data dan sebagainya. 


\section{KESIMPULAN DAN SARAN \\ a. Kesimpulan}

Berdasarkan dari hasil perancangan tersebut dapat diambil sebuah kesimpulan bahwa implementasi wireles mesh network pada ruangan tanpa sekat diprediksi hasilnya lebih maksimal dibandingkan dengan ruangan bertingkat dan bersekat.

\section{b. Saran}

Pada penelitian ini hanya menggunaan satu jenis router untuk implementasi wireless mesh network, diharapkan pada penelitian yang akan datang dapat menggunakan hardware yang berbeda jenis sehingga hasil dari implementasi wireless mesh network dapat berbagai macam.

\section{REFERENSI}

I Putu Eka Agus Pratama\&Sinung Suakanto (2015). Wireless Sensor Network: Informatika Bandung.

Fauzan Fadillah, Istikmal, Ratna Mayasari, Analisis Implementasi Hybrid Wireless Mesh Network Berbasis Standart IEEE 802.11S Menggunakan Protokol Routing OLSR dan AODV, Telkom University, 2012

Fathur Zaini Rachman, Armin, Nur Yanti, Qory Hidayati, Analisi Unjuk Kerja Penjadwalan Terdistribusi Spatial Time Division Multiple Acces Pada Wireless Mesh Network, ISSN: 2355-7699 Vol. 4, No. 3, September 2017

Imam Tri Suryadin, Wing Wahyu Winarno, Sudarmawan, Rancang Bangun Freifunk Pada Wireless Mesh Network DEngan Standart IEEE $802.11 \mathrm{~b} / \mathrm{G}$, Jurnal Ekonomi dan Teknik Informatika Volume 5 Nomor 8 Edisi Februari 2016

Januar Al Amien1, Cuncun Wibowo, Implementasi Wireless Mesh Network Menggunakan Controler Acces Point System Manager di Lingkungan Univeristas Muhammadiyah Riau, Jurnal Fasikom, ISSN : 2089-3353, Vol. 7 Nomor 2 (2018) 255-265

Kasyful Amron, Eko Sakti P., Mahendra Data. Permodelan dan Analisis Wireless Mesh Network dengan Arsitektur Publish-Subceribe dan Protokol MQTT, Jurnal Teknologi Informasi dan Ilmu Komputer (JTIIK), 2016
Nanang Ismail, Adam Faroqi, Lia Kamelia, Rina Mardiati, Simulasi Wireless Mesh Network (WMN) Untuk Mendukung Implementasi Next Generation Network (NGN), ISSN 1979-8911, Volume V No. 1 - 2, 2011

Sofyan Ainurrachman, Adhitya Bhawiyuga, Mochammad Hannats Hanafi Ichsan. Analisis Perbandingan Performansi Protokol Routing OLSR dan SOLSR Pada Wireless Mesh Network, Jurnal Pengembangan Teknologi Informasi dan Ilmu Komputer e-ISSN 2548-964X , 2017

Shinji Sakamoto, Tetsuya Oda, Implementasi dan Evaluasi Sistem Simulasi Berdasarkan Particle Swarm Optimization untuk Node Penempatan Masalah dalam Wireless Mesh Network, International Journal of Communication Networks and Distributed Systems (IJCNDS), Vol. 17, No. 1, 2016

Taufik Hidayat, Hafidudin, Indrarini Dyah Irawati, Implementasi Wireless Mesh Network dengan Prototkol Routing OLSR untuk layanan Video Conference, Telkom University, 2011 